\title{
Comparison of uterine, endometrial and ovarian blood flow by transvaginal color Doppler ultrasound in ovulatory and anovulatory cycles
}

\author{
Ozan Dogan ${ }^{1}$, Ahmet Yildiz², Osman Temizkan ${ }^{3}$, Cigdem Pulatoglu \\ 'Department of Gynecology and Obstetrics, Düzce State Hospital, Düzce, Turkey \\ ${ }^{2}$ Department of Gynecology and Obstetrics, Sakarya Univercity Faculty of Medicine, Sakarya, Turkey \\ ${ }^{3}$ Department of Gynecology and Obstetrics, Sisli Etfal Research and Education Hospital, Turkey
}

\begin{abstract}
Objectives: Blood flow to uterus and ovaries is demonstrated to be altered during mensturation. Studies has been published stating that blood flow differs also in ovulatory and anovulatory cycles. In this study, using color Doppler ultrasound, we aim to compare uterine, endometrial and ovarian blood flow during ovulatory and anovulatory cycles.

Material and methods: Women volunteers who are aged between $18-40$ had no endocrinological problem and not recieving exogenous hormone therapy were included to study. Blood levels of $\mathrm{FSH}, \mathrm{LH}, \mathrm{E2}$, prolactine, DHEAS, free T4 were collected in early follicular phase. Uterina, subendometrial and intraovarian artery blood flow pulsatility and resistance indexes were analysed using Doppler USG technique. Patients were called out to control on 21st of cycle and progesterone levels were analysed. Patients who has ovulation signs in USG and progesterone level above $5 \mathrm{ng} / \mathrm{mL}$ were included to ovulatory cycle group. Patient who has no signs of ovulation in ultrasound and has not enough progesterone level were included to anovulatory cycle group. Results: LH and E2 levels were significantly higher in anovulatory patients. No correlation was found between endometrial blood flow resistance and basal E2, prolactine, testosterone levels. However, DHEAS levels were related to endometrial blood flow resistance in anovulatory cycles. No correlation was found between ovarian blood flow resistance/uterine blood flow resistance and basal E2, prolactine, testosterone, DHEAS levels.

Conclusions: There is statistically significant difference between endometrial, ovarian, uterine artery blood flow resistance in ovulatory and anovulatory cycles. Blood flow resistance was found to be increased in anovulatory patients. Increased E2 levels in anovulatory cycles were related to endometrial linethickness and endometrial volume
\end{abstract}

Key words: ovulation, Doppler ultrasound, anovulation

Ginekologia Polska 2016; 87, 8: 581-584

\section{INTRODUCTION}

Body functions are directly influenced by vascularization. The function of the reproductive system varies greatly throughout the menstrual cycle, for follicular development, ovary and endometrium are dependent on blood flow. Blood flow patterns through the ovary and the endometrium can also change by the new blood vessels and microvascularization. The ovarian tissue during the menstrual cycle undergoes cyclic changes and dynamic processes: follicular development, ovulation, luteal growth, regression, and follicular. Similarly, these cyclic changes can also be seen in the uterus and the endometrium.
The vascularization of the dominant follicle was higher than of other follicles on day 9 of the cycle [1]. Being a part of the corpus luteum cells of the endothelial cells is thought to be evidence of changes in vascularization [2].

Since 1970s, color Doppler ultrasonography has been used during the menstrual cycle as a non-invasive method to monitor uterine and ovarian blood flow [3-6]. With the constant change and development of Doppler ultrasound, and a widespread use of this technique, uterine and ovarian arteries as well as endometrial, sub-endometrial, ovarian artery and ovarian stromal blood flow changes during the menstrual cycle have been shown [5-8]. 
Various studies showing that the ovarian blood flow changes dramatically during the ovulation have been published [9]. Different authors also claim that a decline in the ovarian artery blood flow resistance, which may be associated with ovarian function, has been demonstrated in cycles with ovulation during the luteal phase [5].

In this study, we aimed to compare uterine, endometrial and ovarian blood flow using color Doppler ultrasound during ovulatory and anovulatory cycles.

\section{MATERIAL AND METHODS}

Our study included 86 patients who were admitted to gynecology policlinics of the Sisli Etfal Research and Training Hospital Gynecology Department due to various reasons, between March 1, 2014 and February 1, 2015. Local Ethics Committee approved of the study.

Women (aged 18-40 years) without endocrine disorders such as diabetes, hyperthyroidism, hypothyroidism, hypertension, hyperprolactinemia, polycystic ovary syndrome, and women not using exogenous hormones were included in the study. All participating volunteers gave their informed consent. Age, smoking, secondary diseases, gravidity, parity, and menstrual patterns, were recorded. Weight and height measurements were used to calculate the body mass index (BMI).

Fasting blood samples were taken between 10:00 and 08:00 in the morning. On day 2 of the menstruation, in the early follicular phase, FSH, LH, E2, prolactin, DHEAS, and free testosterone, TSH, free T4 levels were measured. Hormonal measurements were performed using the enzyme immunoassay method (Roche Elecsys 2010, Roche Diagnostics $\mathrm{GmbH}$, Mannheim, Germany).

The patients were examined with transvaginal ultrasound B-mode and color Doppler. Uterine artery, sub-endometrial (spiral arteries) and intraovarian artery blood flow Doppler technique pulsatility index (PI) and resistance (RI) index were measured. Right and left basal ovarian follicular assessment was performed with transvaginal ultrasound. Patients were called back on menstruation day 21 for the analysis of progesterone levels. Transvaginal ultrasonographic evaluation was used to determine whether the participants were ovulating. Rupture of the follicle, follicle shrinkage, presence of the corpus luteum, and fluid in the Douglas pouch, etc., were accepted as signs of the ovulation. Ovulation confirmed on ultrasound and progesterone levels of $>5 \mathrm{ng} / \mathrm{mL}$ were the inclusion criteria for the ovulatory group. Patients with progesterone levels of $<5 \mathrm{ng} / \mathrm{mL}$ and no signs of the ovulation on ultrasound on day 21 of the menstruation constituted the anovulatory group. Volunteers were called back for check-up at the end of the menstruation. Endometrial and ovarian volumes were measured.
Windows SPSS 15.0 was used for statistical analysis. The t-test was used to analyze clinical and biochemical data of the independent groups. The $p$-value of $<0.05$ was considered as statistically significant.

\section{RESULTS}

A total of 86 participants were included in the study and divided into the ovulatory and anovulatory cycle groups. Ovulation was confirmed in the 36 (37.5\%) women while 50 (62.5\%) had anovulatory cycles. Age, BMl, gravidity, parity, and smoking status were assessed in both groups but no statistically significant differences were detected (Table 1).

Mean FSH, LH, TSH, E2, prolactin, FT4, DHEAS, testosterone levels were calculated in the ovulatory and anovulatory patients. Women with the anovulatory cycles were assessed on day 2 of the menstruation and LH and E2 levels were found to be significantly higher (Table 2 ).

Uterine, ovarian and endometrial artery $\mathrm{PI}-\mathrm{R}$ values were lower in the ovulatory patients. Endometrial thickness, endometrial volume, right over volume, and left over volume were also significantly different between the ovulatory and anovulatory groups (Table 3).

No correlation was found between endometrial blood flow resistance, basal E2, prolactin, and testosterone levels. However, DHEAS levels in the anovulatory group were found to be proportional to the endometrial blood flow

\begin{tabular}{|l|c|c|c|}
\hline \multicolumn{4}{|c|}{ Table 1. Characteristic of the study group } \\
\hline & $\begin{array}{c}\text { Ovulatory } \\
\text { cycle (n: 36) }\end{array}$ & $\begin{array}{c}\text { Anovulatory } \\
\text { cycle (n: 50) }\end{array}$ & P result \\
\hline Age & $30.8 \pm 8.3$ & $29.8 \pm 6.8$ & 0.536 \\
\hline BMl [kg/m²] & $25.5 \pm 5.5$ & $26.6 \pm 5.7$ & 0.369 \\
\hline Gravida & $2.4 \pm 2.0$ & $2.1 \pm 1.8$ & 0.458 \\
\hline Parity & $1.6 \pm 1.4$ & $1.4 \pm 1.4$ & 0.595 \\
\hline Smoke & $14(38 \%)$ & $19(38 \%)$ & 0.933 \\
\hline
\end{tabular}

\begin{tabular}{|l|c|c|c|}
\hline \multicolumn{4}{|c|}{ Table 2. Hormone levels of the participants } \\
\hline Hormones & $\begin{array}{c}\text { Ovulatory } \\
\text { cycle (n: 36) }\end{array}$ & $\begin{array}{c}\text { Anovulatory } \\
\text { cycle (n: 50) }\end{array}$ & P result \\
\hline FSH & $7.6 \pm 2.0$ & $7.6 \pm 4.1$ & 0.996 \\
\hline LH & $5.7 \pm 1.6$ & $10.2 \pm 3.9$ & 0.003 \\
\hline TSH & $1.4 \pm 0.9$ & $1.6 \pm 0.87$ & 0.140 \\
\hline E2 & $66.2 \pm 19.2$ & $90.1 \pm 64.4$ & 0.033 \\
\hline Prolactin & $17.0 \pm 6.19$ & $17.7 \pm 6.4$ & 0.503 \\
\hline FT4 & $1.23 \pm 0.85$ & $1.1 \pm 0.19$ & 0.371 \\
\hline DHEAS & $235.1 \pm 79.3$ & $231.0 \pm 55.4$ & 0.779 \\
\hline Testosteron & $39.6 \pm 17.8$ & $47.7 \pm 19.4$ & 0.051 \\
\hline
\end{tabular}


Table 3. Transvaginal ultrasound B-mode and color Doppler results

\begin{tabular}{|l|c|c|c|}
\hline & $\begin{array}{c}\text { Ovulatory } \\
\text { cycle (n: 36) }\end{array}$ & $\begin{array}{c}\text { Anovulatory } \\
\text { cycle (n: 50) }\end{array}$ & P result \\
\hline Uterine artery PI & $1.78 \pm 0.28$ & $1.99 \pm 0.38$ & 0,006 \\
\hline Uterine artery RI & $0.80 \pm 0.12$ & $0.87 \pm 0.08$ & 0.003 \\
\hline Ovary artery PI & $1.73 \pm 1.19$ & $1.90 \pm 0.42$ & 0.030 \\
\hline Ovary artery RI & $0.79 \pm 0.10$ & $0.85 \pm 0.10$ & 0.009 \\
\hline Endometrial artery PI & $1.69 \pm 0.20$ & $1.86 \pm 0.39$ & 0.021 \\
\hline Endometrial artery RI & $0.78 \pm 0.11$ & $0.86 \pm 0.10$ & 0.001 \\
\hline Endometrial thickness & $3.9 \pm 2.5$ & $8.3 \pm 2.5$ & 0.001 \\
\hline Endometrial volume & $1.8 \pm 0.69$ & $2.75 \pm 0.65$ & 0.001 \\
\hline Right ovary volume & $6.1 \pm 1.6$ & $4.6 \pm 1.5$ & 0.001 \\
\hline Left ovary volume & $6.6 \pm 2.6$ & $5.03 \pm 1.65$ & 0.001 \\
\hline
\end{tabular}

Table 4. The effect of hormones on the endometrial artery resistance index

\begin{tabular}{|l|c|}
\hline Hormones & P result \\
\hline E2 & 0.209 \\
\hline Prolactin & 0.808 \\
\hline DHEAS & 0.044 \\
\hline Testosterone & 0.082 \\
\hline
\end{tabular}

Table 5. The effect of hormones on the ovarian artery resistance index

\begin{tabular}{|l|c|}
\hline Hormones & P result \\
\hline E2 & 0.069 \\
\hline Prolactin & 0.781 \\
\hline DHEAS & 0.898 \\
\hline Testosterone & 0.816 \\
\hline
\end{tabular}

Table 6. The effect of hormones on the uterine artery resistance index

\begin{tabular}{|l|c|}
\hline Hormones & P result \\
\hline E2 & 0.494 \\
\hline Prolactin & 0.870 \\
\hline DHEAS & 0.965 \\
\hline Testosterone & 0.231 \\
\hline
\end{tabular}

resistance. No correlation was found between ovarian blood flow resistance and E2, prolactin, DHEAS, and testosterone levels. Also, there was no statistically significant correlation between uterine blood flow resistance and basal E2, prolactin, DHEAS, and testosterone levels (Tables 4-6).

\section{DISCUSSION}

In our study, we detected significant differences between the uterine artery, the ovarian artery, and the endometrial artery blood flow resistance in ovulatory and anovulatory cycles. Blood flow resistance parameters in the anovulatory group were significantly higher as compared to the ovulatory group. The literature offers a number of reports on transvaginal Doppler examination of the uterine, ovarian, and endometrial arteries during a normal menstrual cycle [2, 6, 8-10]. Kutlesic et al., found that ovarian artery stromal blood flow resistance and sub-endometrial artery blood flow resistance in the ovulatory group is lower as compared to the anovulatory group. These authors were not able to find any differences in arcuate artery blood flow resistance. They found that uterine and ovarian artery Doppler ultrasound PI and RI levels, blood flow resistance in the ovulatory groups was lower as compared to the anovulatory groups. In our study, we found that anovulatory group blood flow resistance was higher as compared to the ovulatory group. The same results have been found in IVF patients who had no ovulation and had undergone controlled ovarian hyperstimulation. In the same study by Kutlesic et al., in the ovulatory group, ovarian stromal artery blood flow resistance was proportionate to the E2 levels and inversely correlated with gonadotropin levels. Also, no correlation was found between basal hormone levels and blood flow resistance in the anovulatory group. It has been attributed to several other factors which also affect the ovulation. Nevertheless, blood flow to the uterus and the ovaries was concluded to be influenced by local factors more than hormone levels in circulation. In our study, there was also no correlation between blood flow resistance and basal FSH, LH, E2, and prolactin levels but in anovulatory cycles, DHEAS levels were proportionate to the endometrial blood flow resistance. Dal et al., showed that during the mid-luteal phase of ovulatory cycles, uterine, arcuate, radial and spiral arteries blood flow resistance index is lower than in the anovulatory cycles [11-13]. Merce et al., also investigated intraovarian Doppler velocimetry in ovulatory, dysovulatory, and anovulatory cycles, and found that the luteal phase dominant follicle had lower blood flow resistance, the intraovarian resistance index has not changed in anovulatory cycles, and it is obvious that the absence of the ovulation prevents the change of intraovarian spiral artery network. Blood flow changes in the luteal phase have to be determined by ultrasound to detect the ovulation [14]. In our study, we found the ovulatory cycle blood flow resistance to be lower as compared to the anovulatory cycles.

Estrogen shows its effect on the uterine blood vessels and the endometrium through beta-2E2 receptors. E2 recep- 
tors are found on the walls of the uterine artery, so estrogen has as a direct vasodilator effect on the uterine vessels [15]. In patients with premature ovarian failure, low estrogen levels decrease PI values in the uterine artery [16]. The effect of progesterone on the uterine artery blood flow has been less studied. In cases of luteal insufficiency, using exogenous progesterone levels increases uterine blood flow in the presence of normal estrogen levels [17]. In our study, we found increased endometrial thickness and endometrial volume with elevated E2 levels in the anovulatory group. However, no correlation was found between E2 levels and blood flow resistance in the ovulatory and anovulatory groups.

In various studies, color Doppler ultrasound examination, especially on the side of the dominant follicle, revealed lower blood flow resistance between uterine and ovarian arteries. This is directly related to the fact that local factors of the dominant follicle affect the blood flow [18]. There is no dominant follicle in anovulatory cycles, so the absence of the dominant follicle and local factors is related to increased blood flow resistance. However, in patients with PCOS, who have no ovulation, local factors are related with increased stromal vascularization [19]. Our study demonstrated that local factors can change the blood flow. In this regard, there is a need for a further study.

Numerous reports in the literature state that deficiency of physiological changes of blood flow during the menstrual cycle can cause infertility. Steer et al., showed that increased uterine artery blood flow resistance can cause unexplained infertility [20]. In another study, Taylor et al., found that patients undergoing controlled ovarian hyperstimulation have increased ovarian artery blood flow resistance and low response to in vitro fertilization [21]. Temizkan et al., demonstrated that hyperprolactinemia had a vasoconstrictor effect and was related to increased blood flow resistance [22]. However, in our study there was no correlation between prolactin levels in both groups.

\section{CONCLUSIONS}

There is a statistically significant difference between endometrial, ovarian, uterine artery blood flow resistance in ovulatory and anovulatory cycles. Increased E2 levels in anovulatory cycles were related to endometrial line thickness and endometrial volume. Increased DHEAS levels in anovulatory patients were related to endometrial artery blood flow resistance.

\section{REFERENCES}

1. Zeleznik AJ, Schuler HM, Reichert LE Jr. Gonadotropin-binding sites in the rhesus monkey ovary: role of the vasculature in the selective distribution of human chorionic gonadotropin to the pre-ovulatory follicle. Endocrinology. 1981, 109 (2), 356-362.

2. Lei ZM, Chegini N, Rao CV. Quantitative cell composition of human and bovine corpora lutea from various reproductive states. Biol Reprod. 1991 , 44 (6), 1148-1156.

3. Ziegler WF, Bernstein I, Badger G, Leavitt T, Cerrero ML. Regional hemodynamic adaptation during the menstrual cycle. Obstet Gynecol. 1999, 94 (5 Pt 1), 695-699.

4. Santolaya-Forgas J. Physiology of the menstrual cycle by ultrasonography. J Ultrasound Med. 1992, 11 (4), 139-142.

5. Scholtes MC, Wladimiroff JW, van Rijen HJ, Hop WC. Uterine and ovarian flow velocity waveforms in the normal menstrual cycle: a transvaginal Doppler study. Fertil Steril. 1989, 52 (6), 981-985.

6. Steer CV, Campbell S, Pampiglione JS, Kingsland CR, Mason BA, Collins WP. Transvaginal colour flow imaging of the uterine arteries during the ovarian and menstrual cycles. Hum Reprod. 1990, 5 (4), 391-395.

7. Sladkevicius $P$, Valentin L, Marsal K. Blood flow in the uterine and ovarian arteries during the normal menstrual cycle. Ultrasound Obstet Gynecol. 1993, 3, 199-208.

8. Tan SL, Zaidi J, Campbell S, Doyle P, Collins W. Blood flow changes in the ovarian and uterine arteries during the normal menstrual cycle. Am J Obstet Gynecol. 1996, 175, 625-631.

9. Campbell S, Bourne TH, Waterstone J, [et al.]. Transvaginal color blood flow imaging of the periovulatory follicle. Fert Steril. 1993, 60, 433-438.

10. Cevrioğlu SA. Ovaryan Fizyoloji. In: Çiçek N, Akyürek C, Çelik Ç, Haberal A, eds. Kadın Hastalıkları ve Doğum Bilgisi. Ankara, Güneş Kitabevi 2004, 1062-1074.

11. Engmann $L$, Sladkevicius $P$, Agrawal $R$, [et al.]. The pattern of changes in ovarian stromal and uterine artery blood flow velocities during in vitro fertilization treatment and its relationship with outcome of the cycle. Ultrasound Obstet Gynecol. 1999, 13 (1), 26-33.

12. Kutlesić R, Milosavljević M, Vukomanović P, Stefanović M. Color Doppler imaging and measurements of intraovarian and intrauterine vascularization on basal ultrasound examination in spontaneous ovulatory and anovulatory cycles. Vojnosanit Pregl. 2008, 65 (10), 743-750.

13. Dal J, Vural B, Çalışkan E, Özkan S, Yücesoy İ. Power doppler ultrasound studies of ovarian, uterine and endometrial blood flow in regularly menstruating women with respect to luteal phase defects. Fertil Steril. 2005, 84, 224-227.

14. Merce LT, Garecs D, Barco MJ. Intra-ovarian doppler velocimetry in ovulatory, dysovulatory and anovulatory cycles. Ultrasound Obstet. Gynecol. 1992, 2, 197-202.

15. Perrot-Applanat M, Groyer-Picard MT, Garcia E, Lorenzo F, Milgrom E. Immunocytochemical demonstration of estrogen and progesterone receptors in muscle cells of uterine arteries in rabbits and humans. Endocrinology. 1988, 123 (3), 1511-1519.

16. de Ziegler D, Bessis R, Frydman R. Vascular resistance of uterine arteries: physiological effects of estradiol and progesterone. Fertil Steril. 1991, 55 (4), 775-779.

17. Deichert U, Albrand-Thielmann C, van de Sandt M. Doppler sonographic pelvic blood flow measurements and their prognostic value in terms of luteal phase and implantation. Hum Reprod. 1996, 11 (8), 1591-1593.

18. Kutlešić R, Ljubić A, Milosavljević M, Stefanović M, Vukomanović P. Color Doppler and color Doppler energy imaging and measurements of ovarian stromal blood flow in controlled ovarian hyperstimulation for in vitro fertilization. Med Biol. 2006, 13 (2), 104-108.

19. $\mathrm{Ng} \mathrm{EH}, \mathrm{Chan} \mathrm{CC}$, Yeung WS, Ho PC. Comparison of ovarian stromal blood flow between fertile women with normal ovaries and infertile women with polycystic ovary syndrome. Hum Reprod. 2005, 20 (7), 1881-1886.

20. Steer CV, Tan SL, Mason BA, Campell S. Mid-luteal phase vaginal color Doppler assessment of uterine artery impedance in a subfertile population. Fertil Steril. 1994, 61, 53-58.

21. Taylor KJ, Burns PN, Wells PN, Conway DI, Hull MG. Ultrasound Doppler flow studies of the ovarian and uterine arteries. Br J Obstet Gynaecol. 1985, 92 (3), 240-246.

22. Temizkan O, Temizkan S, Asicioglu O, Aydin K, Kucur S. Color Doppler analysis of uterine, spiral, and intraovarian artery blood flow before and after treatment with cabergoline in hyperprolactinemic patients. Gynecol Endocrinol. 2015, 31 (1), 75-78. doi: 10.3109/09513590.2014.958989. 